\title{
Planar Sleeve Antenna for Low-Band UWB System
}

\author{
Mitsuo Taguchi*(1) and Erfan Rohadi ${ }^{(2)}$ \\ (1) Dept. of Electrical \& Electronic Eng., Nagasaki University, \\ (2) Graduate School of Science and Technology, Nagasaki University \\ 1-14 Bunkyo-machi, Nagasaki-shi, 852-8521, Japan \\ E-mail: ${ }^{(1)}$ mtaguchi@nagasaki-u.ac.jp, ${ }^{(2)}$ d705152h@stcc.nagasaki-u.ac.jp
}

\section{Introduction}

The sleeve antenna is used as the base station antenna of mobile communication system. This is essentially a half-wave dipole antenna fed by a coaxial transmission line [1]. This antenna consists of a thinner radiator and a tubular conductor sleeve. The thinner radiator is the inner conductor of a coaxial transmission line. The sleeve attached around the coaxial transmission line provides effective choking of the RF currents at its own open end and also onehalf of the radiating dipole. The tubular conductor sleeve is shorted to the outer conductor of the coaxial transmission line feeding the sleeve [2].

Authors have numerically and experimentally analyzed the sleeve antenna with two tubular sleeves proposed by Sakuma [3], [4]. The outer conductor of the coaxial transmission line and the hollow larger conductor form the lower sleeve and the inner conductor of transmission line and the hollow larger conductor form the upper sleeve. This antenna has the wideband return loss characteristics around resonant frequencies of two sleeves. However, the radiation characteristics of this antenna have not been discussed. Then, the authors have been analyzed the planar sleeve antenna exited by the coplanar waveguide (CPW) [5]. The sleeve antenna is printed on the dielectric plate and two planar sleeves are located outside of the CPW. The effect of sleeves is discussed from the calculated current distribution on the CPW and the radiation patterns. The open ends of two sleeves are aligned on the same position of the CPW and two sleeves are attached on the upper radiator extended from the central conductor of the CPW. This type of sleeve antenna has almost same radiation pattern and good return loss characteristics from $3.4 \mathrm{GHz}$ to $4.0 \mathrm{GHz}$.

In this paper, the planar sleeve antenna exited by the CPW is analyzed from the standpoints of return loss characteristics and radiation characteristics. The sleeve antenna is printed on the dielectric plate and three planar sleeves are located outside of the CPW [6]. The open ends of three sleeves are aligned on the same position of the CPW and three sleeves are attached on the upper radiator extended from the central conductor of the CPW. From the calculated current distribution on the $\mathrm{CPW}$, the leakage current on the $\mathrm{CPW}$ flowing from the sleeve radiator is investigated. The design frequencies of three sleeves are $3.5 \mathrm{GHz}, 4.0 \mathrm{GHz}$ and 4.5 GHz. The effect of sleeves is discussed from the calculated current distribution on the antenna and the radiation patterns. For the preliminary design of the $\mathrm{CPW}$, the electromagnetic simulator TX-line calculator is used [7]. In the 
calculation of the sleeve antenna, the electromagnetic simulator IE3D based on the method of moment is used [8].

\section{Analytical Model}

Figure 1 shows the structure of planar sleeve antenna fed by the CPW. This antenna is printed on the infinite dielectric plate. At first, the geometry of the CPW is designed by using the electromagnetic simulator TX-line calculator so that its characteristic impedance becomes $50 \Omega$. Since the infinite width of side conductors are assumed in TX-line calculator, the characteristic impedance of the $\mathrm{CPW}$ is calculated by using IE3D in order to determine the exact width of the side conductors. The length of the CPW B is $60 \mathrm{~mm}$. The width of central and side conductors of the CPW W1 and $\mathrm{W} 2$ are $4.5 \mathrm{~mm}$ and $6 \mathrm{~mm}$, respectively. The gap width between sleeves $\mathrm{g} 1$ is $0.2 \mathrm{~mm}$ and the gap width between first sleeve L1 and outer edge of side conductor $\mathrm{g} 2$ is $0.4 \mathrm{~mm}$. The

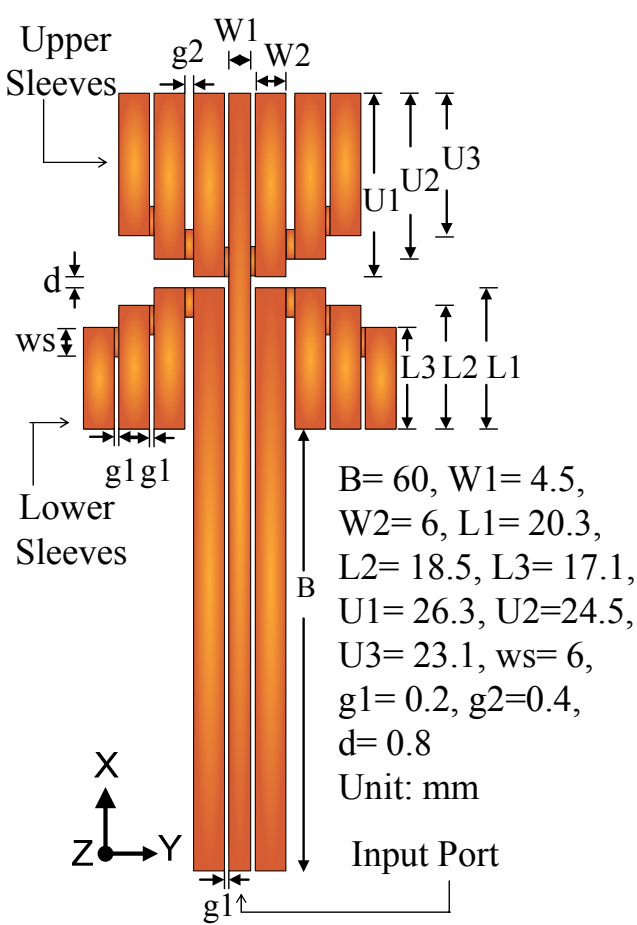

Fig. 1 Structure of planar sleeve antenna thickness and the relative permittivity of dielectric plate are $1 \mathrm{~mm}$ and $\varepsilon_{\mathrm{r}}=4.5$, respectively. In the numerical calculation by IE3D, the dielectric plate is assumed to be lossless. The thickness of metal conductor is $0.018 \mathrm{~mm}$. This antenna has three sleeves outside of the CPW. The design frequency of sleeve is estimated from the frequency when the gap length becomes a quarter wavelength of calculated current distribution. The design frequencies of three sleeves are 3.5 $\mathrm{GHz}, 4.0 \mathrm{GHz}$ and $4.5 \mathrm{GHz}$.

\section{Results and Discussion}

Figure 2 shows the calculated current amplitude distributions on the sleeve antenna. The current amplitude on the CPW becomes small at frequencies from $3.4 \mathrm{GHz}$ to $4.8 \mathrm{GHz}$. Figure 3 show the current amplitude distributions on the edge of central conductor and the inner and outer edge of the side conductor of the $\mathrm{CPW}$ at the design frequencies $3.5 \mathrm{GHz}, 4.0 \mathrm{GHz}$ and $4.5 \mathrm{GHz}$. The leakage current flowing from sleeve along the outer edge of side conductor is small compared with the transmission line mode current. Figure 4 shows the calculated electric field radiation patterns in $\mathrm{xz}$ plane. From $4.5 \mathrm{GHz}$ to $4.8 \mathrm{GHz}$ the radiation patterns are deformed. Figure 5 and 6 show the calculated return loss and input impedance characteristics of the antenna, respectively. 


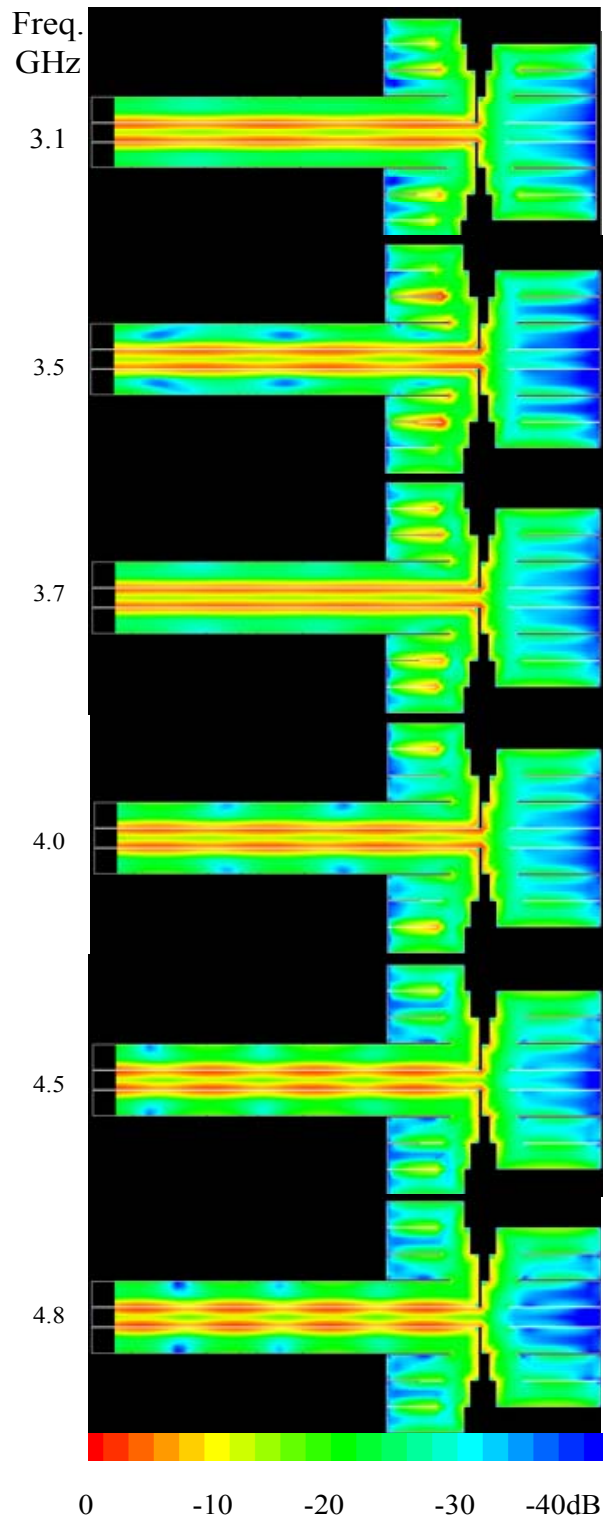

Fig. 2 Calculated current amplitude distribution.

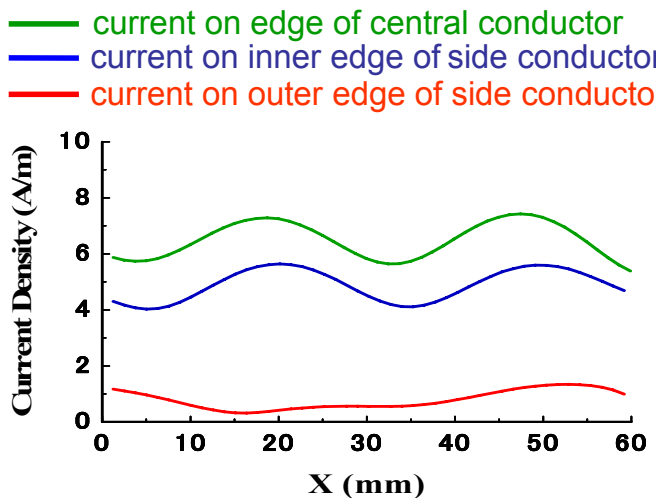

(a) $3.5 \mathrm{GHz}$

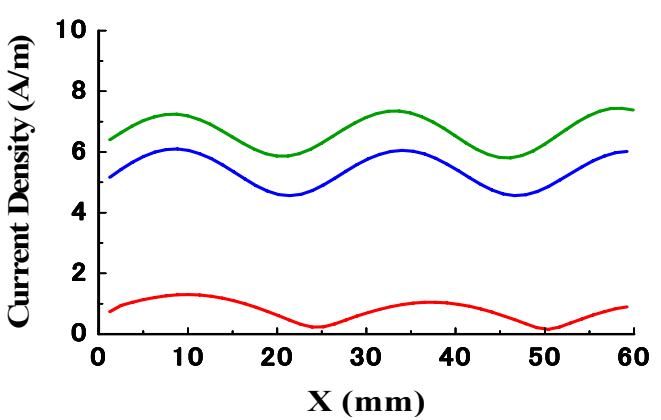

(a) $4.0 \mathrm{GHz}$

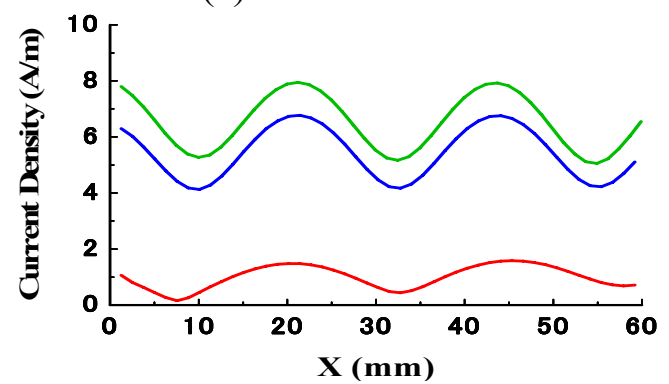

(c) $4.5 \mathrm{GHz}$

Fig. 3 Current amplitude distribution on CPW.

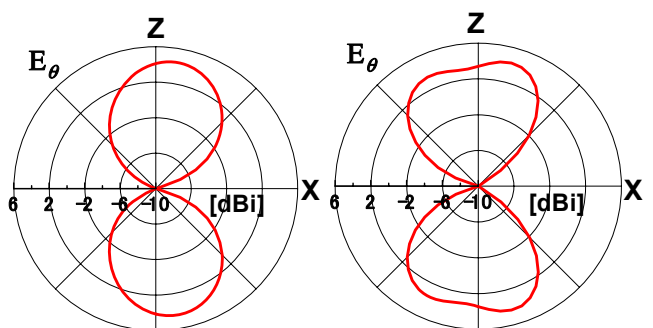

(a) $3.1 \mathrm{GHz}$

(b) $3.5 \mathrm{GHz}$
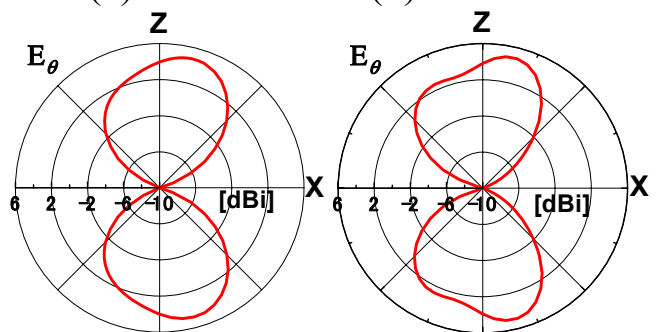

$\begin{array}{ll}\text { (c) } 3.7 \mathrm{GHz} & \text { (d) } 4.0 \mathrm{GHz}\end{array}$

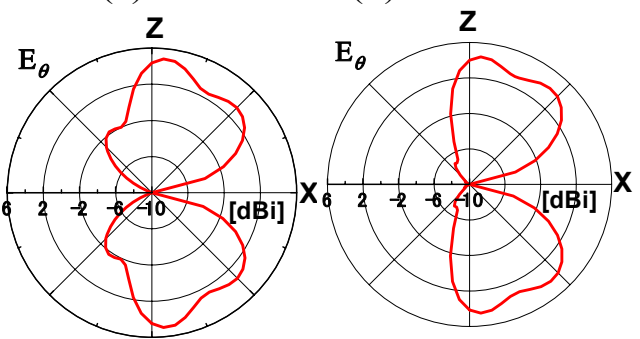

$\begin{array}{ll}\text { (e) } 4.5 \mathrm{GHz} & \text { (f) } 4.8 \mathrm{GHz}\end{array}$

Fig. 4 Electric field radiation patterns in xz plane. 


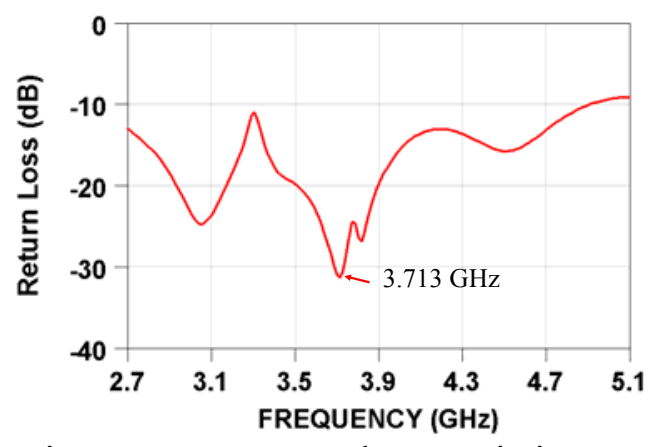

Fig. 5 Return Loss characteristics.

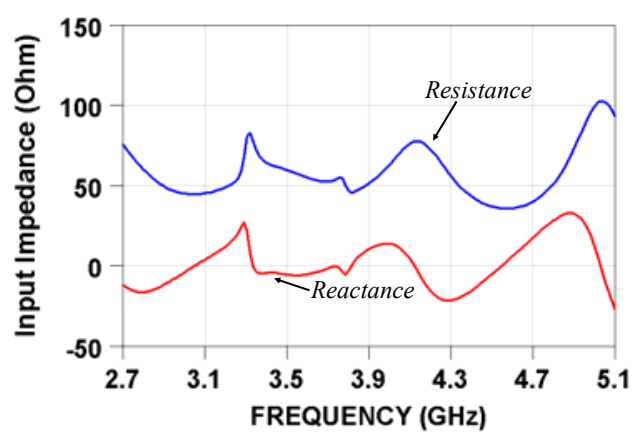

Fig. 6 Input Impedance characteristics.

\section{Conclusion}

The planar sleeve antenna printed on the dielectric plate has been analyzed numerically. This antenna has three sleeves outside of the CPW feed line. The design frequencies of three sleeves are $3.5 \mathrm{GHz}, 4.0 \mathrm{GHz}$ and $4.5 \mathrm{GHz}$. For the preliminary design of the CPW, the electromagnetic simulator TX-line calculator has been used. In the calculation of the sleeve antenna, the electromagnetic simulator IE3D based on the method of moment has been used. From the calculated current distribution and the radiation pattern, the effect of sleeves has been investigated. At the design frequencies, the leakage current on the CPW flowing from the sleeves becomes small. In order to improve the return loss characteristics at the lower frequencies, the open end of three sleeves are aligned on the same position of the CPW and three sleeves are attached on the upper radiator extended from the central conductor of the CPW. The proposed sleeve antenna has almost same radiation pattern and good return loss characteristics in the frequency band of the low-band UWB system. The measured characteristics of this antenna will be shown at the conference.

\section{References:}

[1] Q. Balzano, Design Techniques for Portable Phone Antennas in Mobile Antenna Systems Handbook, pp. 313-320, edited by K. Fujimoto and J. R. James, Boston: Artech House, Massachusetts, 2001.

[2] G. Sato, H. Kawakami and M. Taguchi: Modern Antenna Engineering, Tokyo: Sogo-denshi shuppan, 2004 (in Japanese).

[3] M. Sakuma, Wideband Sleeve Antenna, Japan Patent Application, No. S291001002, Sept. 2003.

[4] M. Taguchi, A. Koga and M. Sakuma, "Wideband Sleeve Antenna", Int. Journal of Microwave \& Optical Technology, vol. 1, no. 2, pp. 801-806, Aug. 2006.

[5] M. Taguchi and E. Rohadi, "Analysis of planar sleeve antenna”, Proc. of 2006 Int. Symp. on Antennas and Propagation, Singapore, Nov. 2006.

[6] R. N. Simons, Coplanar Waveguide Circuits, Components and Systems, John Wiley \& Sons, 2001.

[7] http://web.appwave.com/Products/txline.html.

[8] “IE3D User's Manual Release 9”, Zeland Software, Inc., 2002. 